\title{
EVALUATION OF MENORRHAGIA AND ITS CORRELATION WITH HYSTEROSCOPY AND HISTOPATHOLOGY OF ENDOMETRIUM
}

\author{
Neelam Tejwani ${ }^{1}$, Rahul Padval2 ${ }^{2}$ P. K. Roy ${ }^{3}$ \\ ${ }_{1}^{1}$ Associate Professor, Department of Obstetrics and Gynaecology, R. D. Gardi Medical College, Ujjain. \\ ${ }^{2}$ Consulting Gynaecologist, Department of Obstetrics and Gynaecology, Dahod District Hospital. \\ 3Professor, Department of Obstetrics and Gynaecology, R. D. Gardi Medical College, Ujjain.
}

ABSTRACT

\section{BACKGROUND}

Menorrhagia is one of the most frequent complaint among women to see a gynaecologist. Clinically menorrhagia is total blood loss

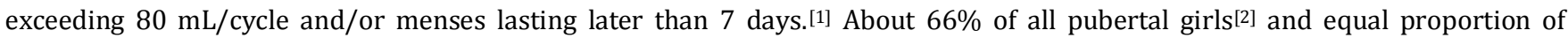
women in reproductive age group[3] have complaints of heavy menstrual flow. Figure could be as high as $15 \%$ in perimenopausal women. ${ }^{[4]}$ Dysfunctional uterine bleeding (DUB) is the diagnosis of exclusion in $60 \%$ of women.[5] To ascertain the exact causative factor of menorrhagia, different investigation methods are available like ultrasonography, hysteroscopy, dilatation and curettage (D \& C) and histopathology of endometrium.

The aim of the study is to know the best method among available methods and to compare diagnostic potential of hysteroscopy versus D\&C followed by histopathology. Exact and timely diagnosis can prevent women from unnecessary hysterectomy.

\section{MATERIALS AND METHODS}

This is a prospective observational study conducted in R.D. Gardi Medical College. 97 women attending GYN Outpatient Department (OPD) between 01-09-2011 to 01-03-2013 complaining of DUB were included. In this study, in all patients, hysteroscopy and histopathology of endometrium after D\&C was done to diagnose underlying pathology.

\section{RESULTS}

Results were compared between 2 methods for assessing DUB causing pathological factors.

\section{CONCLUSION}

Hysteroscopy is nowadays an office procedure, which is convenient and easily available and gives a lot of information, but old is gold, D\&C and histopathology give detailed information of hormonal status of endometrium and also of many conditions like polyp, endometrial hyperplasia. So, pros and cons of every procedure should be weighed and accordingly can be used to assess abnormal uterine bleeding (AUB).

\section{KEYWORDS}

Dilatation and Curettage, Histopathology, Hysteroscopy, AUB, Menorrhagia.

HOW TO CITE THIS ARTICLE: Tejwani N, Padval R, Roy PK. Evaluation of menorrhagia and its correlation with hysteroscopy and histopathology of endometrium. J. Evolution Med. Dent. Sci. 2017;6(91):6443-6448, DOI: 10.14260/jemds/2017/1401

\section{BACKGROUND}

The goals of clinical management are mainly dependent upon correct aetiological diagnosis. History, physical and pelvic examination attempt to determine the site of bleeding.

\section{Modalities available for AUB Diagnosis are-}

1. Invasive - dilatation and curettage (D \& C).

2. Non-invasive - saline infusion sonography (SIS).

3. Minimal invasive - Hysteroscopy.

Early modalities have their own advantages and disadvantages.

'Financial or Other Competing Interest': None.

Submission 18-10-2017, Peer Review 11-11-2017,

Acceptance 17-11-2017, Published 27-11-2017.

Corresponding Author:

Dr. P. K. Roy,

Professor,

Department of Obstetrics and Gynaecology,

R. D. Gardi Medical College,

Ujjain,

Madhya Pradesh.

E-mail: colpkroy@gmail.com

DOI: $10.14260 /$ jemds $/ 2017 / 1401$

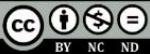

3D saline infusion sonography (SIS) is a newer technique. Other newer techniques are: Use of biochemistry, histochemistry, immunohistochemistry and electron microscopy. USG is an excellent method, especially transvaginal sonography (TVS). It improves inspection of endometrium and ovaries. However, evaluation of uterine cavity is limited. By hysteroscopy, intrauterine abnormalities can be assessed and endometrial and myometrial abnormalities cannot always be differentiated. SIS improves diagnosis. Hysteroscopy is an office procedure and is well accepted.

D \& C was the primary method of evaluating abnormal uterine bleeding. Half of the abnormalities such as endometrial polyp and hyperplasia were managed by curettage. The problem of endometrial sampling is that it is blind and incomplete, so diagnostic accuracy of D\&C is less than hysteroscopy. For focal lesion D\&C is less accurate, but for histopathological diagnosis it is of immense importance.

\section{Aims and Objectives}

- Hysteroscopic evaluation of uterine cavity in patients of menorrhagia and its correlation with histopathology of endometrium. 
- To formulate a plan for evaluation of case of primary menorrhagia based on findings of hysteroscopy and histopathology.

\section{MATERIALS AND METHODS}

This was a prospective observational study conducted on 97 women with history of menorrhagia presenting to Gynaecological OPD and wards of Department of Obstetrics and Gynaecology, R. D. Gardi Medical College.

Hysteroscopy was done in 50 patients of AUB (abnormal uterine bleeding). The study was done between 01-09-2011 to 01-03-2013. All patients underwent thorough physical examination and detailed history taken with routine investigations. All those subjects who fulfilled the eligibility criteria were subjected to clinical examination, saline infusion ultrasonography, hysteroscopy and histopathological examination.

Abdominal and vaginal sonography was done to note uterus (size, position, endometrial thickness), ovaries (size follicular development), adnexa and pouch of Douglas. Saline infusion sonography was done by instilling normal saline into Foley catheter No.8. TVS probe 8-13 MHz attached with LOGIQ P6 model of ultrasonography machine of general electronics.

All women underwent diagnostic hysteroscopy by 0 \& 30 hysteroscope for assessing endometrial lining, submucous fibroid and endometrial polyp. Results of SIS and hysteroscopy were compared to detect normal and abnormal findings in terms of sensitivity, specificity, positive predictive value, negative predictive value, accuracy, false negative results, and likelihood ratio (LR Ratio). P value less than 0.05 was considered significant. Data so collected was entered simultaneously into "statistical package for social scientists" (SPSS) software version 23.0 and coded appropriately. Advice of statistician was taken. Chi square was used for significant correlation of data. Data was entered in MS Excel spread sheet and analysis was done using SPSS 23.0. P value $<0.05$ was considered significant.

\section{Inclusion Criteria}

Women aged between 18-50 yrs., married, with history of menorrhagia.

\section{Exclusion Criteria}

Unwilling women, unmarried, active cervical and uterine infection or any Pelvic malignancy.

\section{Ethical Aspect}

Patients were explained about the study and informed consent was taken. The proposal was cleared by the institutional ethical committee.

\section{Review of Literature}

To understand abnormal uterine bleeding (AUB), a common clinical problem with myriad causes, a solid knowledge of menstrual physiology and a thorough approach to differential diagnosis is essential to evaluate and manage the problem with confidence.

As per Federation of International Gynaecologists and Obstetricians (FIGO) classification system, there are 9 main categories, which are arranged according to the acronym PALM-COEIN (pronounced "palm-koin"): Polyp;
Adenomyosis; Leiomyoma; Malignancy and Hyperplasia; Coagulopathy; Ovulatory dysfunction; Endometrial; Iatrogenic; and Not yet classified which are responsible for AUB. [6]

\section{Polyp (AUB-P)}

These epithelial proliferations comprise variable vascular, glandular, and fibromuscular and connective tissue component and are often asymptomatic, but it is generally accepted that at least some contribute to DUB, very well diagnosed by hysteroscopy and can be managed by D\&C in some cases.

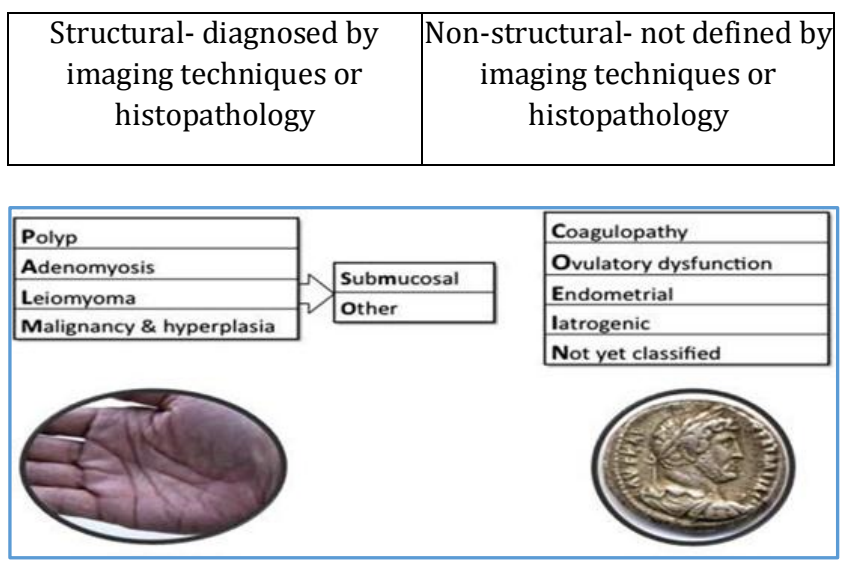

Figure 1. FIGO Classification System for Causes of AUB

\section{Ovulatory Dysfunctional Bleeding}

Although less common than anovulatory bleeding, ovulatory DUB may also occur. DUB in women with ovulatory cycles occurs as regular, cyclic bleeding. Menorrhagia may signify a bleeding disorder or a structural lesion, such as uterine leiomyoma, adenomyosis or endometrial polyps.[7]

Midcycle spotting may result from the rapid decline in oestrogen levels before ovulation. An endometrial biopsy should be considered early in the evaluative process of women who have a history of prolonged exposure to unopposed oestrogen, who do not respond to initial management strategies .

\section{Characteristics of Ovulatory and Anovulatory cycles Ovulatory cycles $(\mathbf{1 0 \%})$}

1. Regular cycle length.

2. Presence of premenstrual symptoms.

3. Dysmenorrhea.

4. Breast tenderness.

5. Change in cervical mucus.

6. Mittleschmerz.

7. Biphasic temperature curve.

\section{Anovulatory cycles (90\%)}

1. Unpredictable cycle length.

2. Unpredictable bleeding pattern.

3. Frequent spotting.

4. Infrequent heavy bleeding.

5. Monophasic temperature curve.

\section{Perimenopausal Women}

As women approach menopause, cycles shorten and often become intermittently anovulatory. These changes are the 
result of a decline in the number of ovarian follicles and in the oestradiol level. As follicles decrease in number, the level of follicle-stimulating hormone needed to stimulate ovulation increases.

\section{Excluding Endometrial Carcinoma}

All perimenopausal women with persistent abnormal uterine bleeding should be evaluated for the presence of endometrial hyperplasia or carcinoma. Endometrial biopsy is the most widely used and best studied method of excluding endometrial carcinoma in this age group. In women with normal findings on biopsy, treatment usually consists of monthly progesterone withdrawal or low-dose oral contraceptives. If bleeding continues despite hormonal therapy, further investigation is warranted.

\section{Hysteroscopy}

Hysteroscopy with biopsy allows visualisation of the endometrial cavity and is regarded as the "gold standard" for endometrial assessment. Diagnostic hysteroscopy can be performed in an office setting and requires no anaesthesia or sedation. Operative hysteroscopy utilises a rigid scope with a fluid distending medium and is useful for diagnosis and treatment. Before hysteroscopy was available, curettage was the primary method of evaluating abnormal uterine bleeding. Curettage, however, renders endometrial sampling blind and incomplete, so the diagnostic accuracy of curettage is less than that of hysteroscopy. ${ }^{[8],[9]}$

In some instances, disorder may be iatrogenic caused by gonadal steroids or drugs that impact dopamine metabolism such as phenothiazine and tricyclic antidepressant.
When AUB occurs in the form of predictable and cyclical menstrual bleeding, typical of ovulatory cycles and no other definite cause can be found, it is probably a disorder of endometrium.

There may be other primary disorders of endometrium that do not present as heavy blood flow but instead may cause intermediate blood loss (IMB) or prolonged bleeding, the latter of which may be manifestation of deficiency in the molecular mechanism of endometrial repair, such disorder may be secondary to endometrial inflammation or infection; abnormality in local inflammatory response or a serration in endometrial vasculogenesis.

Retrospective evaluation of women with chronic endometritis has failed to demonstrate a consistent relationship between histopathological diagnosis and presence of AUB[10],[11] but there are data indicating relation between otherwise subclinical infection with Chlamydia trachomatis and AUB.

Unscheduled bleeding of endometrium that occurs during use of gonadal steroid therapy is termed breakthrough bleeding (BTB) and is a major component of AUB. Woman receiving hormonal replacement therapy often present with AUB and of these $30 \%$ have uterine pathology. The causes may be cervical lesion, vaginal pathology or hormone therapy itself. Women receiving sequential hormonal replacement therapy may experience midcycle bleed due to missed pill. IUCD copper or hormonal issues also may be the cause in some cases.

\section{RESULTS}

\begin{tabular}{|c|c|c|c|c|c|}
\hline \multirow{2}{*}{ Characteristics Tested } & \multicolumn{5}{|c|}{ SIS and Hysteroscopy } \\
\cline { 2 - 6 } & Overall & Normal & Polyp & S. Fibroid & E. Hyperplasia \\
\hline Sensitivity & 100 & 96.29 & 96.29 & 95.23 & 80 \\
\hline Specificity & 95.34 & 97.14 & 97.14 & 94.73 & 100 \\
\hline Positive predictive value(PPV) & 96.42 & 92.85 & 92.85 & 83.33 & 100 \\
\hline Negative predictive value(NPV) & 100 & 98.55 & 98.55 & 98.63 & 08.92 \\
\hline False Positive Rate (FPR) & 4.65 & 2.85 & 2.85 & 5.26 & 20 \\
\hline False Negative rate(FNR) & 0 & 3.7 & 3.7 & 4.7 & 98.96 \\
\hline Concordance (Accuracy) & 97.93 & 96.9 & 96.9 & 94.84 & 28.33 \\
\hline Likelihood ratio(LR) & 194.964 & 89.86 & 89.86 & 69.15 & 0 \\
\hline Fisher's Exact Test & \multicolumn{7}{|c|}{ Morphological Lesion in Uterus } & & $<0.01$ & \\
\hline \multicolumn{7}{|c|}{ P Value } & $<0.001$ & $<0.01$ & $<0.01$ & & \\
\hline
\end{tabular}

\begin{tabular}{|c|c|c|c|c|c|}
\hline & & \multicolumn{2}{|c|}{ Histopathology to Detect Normal Findings } & \multirow[b]{2}{*}{ Total } & p value \\
\hline & & Present & Absent & & \multirow{4}{*}{$<0.01$} \\
\hline \multirow{2}{*}{ Hysteroscopy } & Present & 41 & 2 & 43 & \\
\hline & Absent & 6 & 48 & 54 & \\
\hline Total & & 47 & 50 & 97 & \\
\hline
\end{tabular}




\begin{tabular}{|c|c|}
\hline Sensitivity & 87.2 \\
\hline Specificity & 96 \\
\hline Positive Predictive Value (PPV) & 95.3 \\
\hline Negative Predictive Value (NPV) & 88.8 \\
\hline False Positive Rate (FPR) & 4 \\
\hline False Negative Rate (FNR) & 12.7 \\
\hline Concordance (Accuracy) & 91.7 \\
\hline
\end{tabular}

\begin{tabular}{|c|c|c|c|c|c|}
\hline & & \multicolumn{2}{|c|}{ Histopathology to Detect Polyp } & \multirow[b]{2}{*}{ Total } & p value \\
\hline & & Present & Absent & & \multirow{4}{*}{$<0.01$} \\
\hline \multirow{2}{*}{ Hysteroscopy } & Present & 17 & 10 & 27 & \\
\hline & Absent & 2 & 68 & 70 & \\
\hline Total & & 19 & 78 & 97 & \\
\hline
\end{tabular}

\begin{tabular}{|c|l|}
\hline Sensitivity & 89.4 \\
\hline Specificity & 87.1 \\
\hline Positive Predictive Value (PPV) & 62.9 \\
\hline Negative Predictive Value (NPV) & 97.1 \\
\hline False Positive Rate (FPR) & 12.8 \\
\hline False Negative Rate (FNR) & 10.5 \\
\hline Concordance (Accuracy) & 87.6 \\
\hline
\end{tabular}

\begin{tabular}{|c|c|c|c|c|c|}
\hline & & \multicolumn{2}{|c|}{ Histopathology to Detect Submucous Fibroid } & \multirow[b]{2}{*}{ Total } & p value \\
\hline & & Present & Absent & & \multirow{4}{*}{$<0.01$} \\
\hline \multirow{2}{*}{ Hysteroscopy } & Present & 14 & 7 & 21 & \\
\hline & Absent & 3 & 73 & 76 & \\
\hline Total & & 17 & 80 & 97 & \\
\hline
\end{tabular}

\begin{tabular}{|c|c|}
\hline Sensitivity & 82.3 \\
\hline Specificity & 91.2 \\
\hline Positive Predictive Value (PPV) & 66.6 \\
\hline Negative Predictive Value (NPV) & 96 \\
\hline False Positive Rate (FPR) & 8.7 \\
\hline False Negative Rate (FNR) & 17.6 \\
\hline Concordance (Accuracy) & 89.6 \\
\hline
\end{tabular}

\begin{tabular}{|c|c|c|c|c|c|}
\hline & & \multicolumn{2}{|c|}{$\begin{array}{c}\text { Histopathology to } \\
\text { Detect Endometrial Hyperplasia }\end{array}$} & \multirow[b]{2}{*}{ Total } & $p$ value \\
\hline & & Present & Absent & & \multirow{4}{*}{$<0.01$} \\
\hline \multirow{2}{*}{ Hysteroscopy } & Present & 4 & 1 & 5 & \\
\hline & Absent & 9 & 83 & 92 & \\
\hline Total & & 13 & 84 & 97 & \\
\hline
\end{tabular}

\begin{tabular}{|c|c|}
\hline Sensitivity & 30.7 \\
\hline Specificity & 98.8 \\
\hline Positive Predictive Value (PPV) & 80 \\
\hline Negative Predictive Value (NPV) & 90.2 \\
\hline False Positive Rate (FPR) & 1.1 \\
\hline False Negative Rate (FNR) & 69.2 \\
\hline Concordance (Accuracy) & 89.6 \\
\hline
\end{tabular}




\begin{tabular}{|c|c|c|c|c|c|}
\hline \multirow{2}{*}{ Characteristic tested } & \multicolumn{5}{|c|}{ SIS and Histopathology } \\
\hline & Overall & Normal & Polyp & S. Fibroid & E. Hyperplasia \\
\hline Sensitivity & 96 & 82.97 & 100 & 88.23 & 30.76 \\
\hline Specificity & 82.97 & 96 & 88.46 & 88.75 & 100 \\
\hline Positive predictive value(PPV) & 85.71 & 95.12 & 67.85 & 62.5 & 100 \\
\hline Negative predictive value(NPV) & 95.12 & 85.71 & 100 & 97.26 & 90.32 \\
\hline False Positive Rate (FPR) & 17.02 & 4 & 11.53 & 11.25 & 0 \\
\hline False Negative rate(FNR) & 4 & 17.02 & 0 & 11.76 & 69.23 \\
\hline Concordance (Accuracy) & 89.69 & 89.69 & 90.72 & 88.65 & 90.72 \\
\hline Likelihood ratio(LR) & 140.4 & 72.46 & 60.79 & 39.95 & 17.29 \\
\hline Fisher's Exact Test & & & & 0 & 0 \\
\hline P Value & $<0.001$ & $<0.01$ & $<0.01$ & & \\
\hline & & DIs un & $\begin{array}{l}\text { oscopy } \\
\text { I in Ute }\end{array}$ & & jically proved \\
\hline
\end{tabular}

\section{DISCUSSION}

Endometrial assessment is performed to diagnose malignancy or premalignant condition and to evaluate hormonal influence of endometrium. Sampling of endometrium should be considered in all woman $>40$ years age with AUB including nulliparity with a history of infertility, new onset of heavy irregular bleeding, obesity, PCOD or family history of endometrial cancer.[12],[13],[14],,[15],[16],[17]

It is also important to evaluate endometrial histopathology in woman who has no improvement in her bleeding pattern following a course of 3-month therapy.

\section{FIGO has classified AUB in Two Aetiological Groups}

I. PALM (structural lesions- via Polyp, adenomyosis, leiomyoma, malignancy, and hyperplasia.)

II. COEIN 0 (Non-structural lesions- via coagulopathy, ovulatory dysfunction, endometrial, iatrogenic, not yet classified.

In the present study, diagnostic utility of hysteroscopy and histopathology of endometrium sampling by D\&C done were discussed.

In the present study analysis of hysteroscopy out of total ( $\mathrm{n}=97$ ) subjects, $44 \%$ had normal findings, while abnormal findings i.e. $23.7 \%$ polyps, $21.6 \%$ submucous fibroids, $5.1 \%$ endometrial hyperplasia and 1 abnormal finding include placental polyp which on SIS was diagnosed as submucous fibroid.

In the present study analysis of histopathology out of total ( $\mathrm{n}=97$ ) subjects, $48 \%$ had normal endometrium findings, while $13.4 \%$ had endometrial hyperplasia. In the present study, final diagnosis was made after histopathology and comparison with hysteroscopy.

In the present study, on comparison of Hysteroscopy with respect to Histopathology to detect polyps, Sensitivity was 89.47\%, Specificity $87.17 \%$, Positive Predictive Value (PPV) 62.96\%, Negative Predictive Value (NPV) $97.14 \%$ and Concordance (Accuracy) was 87.62 with $p$ value $<0.01$.

On comparison of Hysteroscopy with respect to Histopathology to detect submucous fibroid, Sensitivity was 82.35\%, Specificity 91.25\%, Positive Predictive Value (PPV) $66.66 \%$, Negative Predictive Value (NPV) $96.05 \%$ and Concordance (Accuracy) was 89.69 with p value $<0.01$.

On comparison of Hysteroscopy with Histopathology to detect endometrial hyperplasia, Sensitivity was 30.76\%, Specificity 98.80\%, Positive Predictive Value (PPV) 90.21\%, Negative Predictive Value (NPV) $80 \%$ and Concordance (Accuracy) was 89.69 and $p$ value $<0.01$.
Overall Sensitivity, Specificity, Positive Predictive Value (PPV), Negative Predictive Value (NPV) and Concordance (Accuracy) was 96\%, 87.23\%, 88.88\%, 95.34\% and 91.75 respectively with respect to histopathology which was comparable to other studies.

\section{CONCLUSION}

- Menorrhagia is more common in reproductive age group of 20-40 years of age with mean age of 36.4 years.

- Menorrhagia is more common in women with parity $\geq 2$.

- Majority of women seek treatment for menorrhagia within one year of onset of complaint.

- Out of 97 patients ( $n=97$ ), by Hysteroscopy $44 \%$ had normal findings and $55.6 \%$ had abnormal findings.

- $\quad$ For polyps, Hysteroscopy had sensitivity of $89.47 \%$ and specificity $87.17 \%$, while SIS had sensitivity of $100 \%$ and specificity $88.46 \%$ with significant $p$ value $(<0.01)$.

- For submucous fibroids, Hysteroscopy had sensitivity of $82.35 \%$ and specificity $91.25 \%$ while SIS had sensitivity of $88.23 \%$ and specificity $88.75 \%$ with significant $p$ value $(<0.01)$.

- For endometrial hyperplasia, Hysteroscopy had sensitivity of $30.76 \%$ and specificity $98.8 \%$ while SIS had sensitivity of $30.76 \%$ and specificity $100 \%$ with significant $p$ value $(<0.01)$.

- Hysteroscopy had overall sensitivity of $96 \%$, specificity 87.23\%, PPV 88.88\%, NPV 95.34\% with accuracy 91.75 to detect normal and abnormal pathology as compared to histopathology ( $\mathrm{p}$ value $<0.01$ ).

- Hysteroscopy is the gold standard in evaluation of AUB and besides diagnostic accuracy it offers definitive management.

- D\&C and histopathology of the endometrium gives definitive diagnosis in cases like endometrium CA, but it is tedious to admit the patient and do D\&C under GA as compared to hysteroscopy which is an office procedure.

\section{REFERENCES}

[1] Hallberg L, Nilsson L. Determination of menstrual blood loss. Scand J Clin Lab Invest 1964;16:244-8.

[2] Sheila W, Malathy K, Premila S. Menstrual and gynecological disorders in 500 school girls in Madras city. J Obstet Gynecol India 1993;43:940-5.

[3] Royal College of General Practitioners, Office of Population Censuses and Surveys and Department of Health. Morbidity statistics from general practice. Third national study, 1981-82, Series MB5 no 1. London: HMSO; 1986. 
[4] Horn SD, Prather S, Jones CA. A cohort analysis of premenopausal women with dysfunctional uterine bleeding. HMO Pract 1996;10(2):59-64.

[5] Beazley JM. Dysfunctional uterine haemorrhage. Br J Hosp Med 1972;7:573-8.

[6] Munro MG, Critchley HO, Fraser IS. The FIGO classification of causes of abnormal uterine bleeding in the reproductive years. Fertil Steril 2011;95(7):22048.

[7] Speroff L, Fritz MA. Clinical gynecologic endocrinology and infertility. $7^{\text {th }}$ edn. Philadelphia: Lippincott Williams \& Wilkins, 2005:531-72.

[8] Chuong CJ, Brenner PF. Management of abnormal uterine bleeding. Am J Obstet Gynecol 1996;175(3 Pt 2):787-92.

[9] De Wit AC, Vleugels MP, de Kruif JH. Diagnostic hysteroscopy: a valuable diagnostic tool in the diagnosis of structural intra-cavital pathology and endometrial hyperplasia or carcinoma? Six years of experience with non-clinical diagnostic hysteroscopy. Eur J Obstet Gynecol Reprod Biol 2003;110(1):79-82.

[10] Heatley MK. The association between clinical and pathological features in histologically identified chronic endometritis. J Obstet Gynaecol 2004;24(7):801-3.
[11] Munro MG. Abnormal uterine bleeding in the reproductive years. Part 1: pathogenesis and clinical investigations. J Am Assoc Gynecol Laparoscop 1999;6(4):391-419.

[12] Farquhar CM, Lethaby A, Sowter M, et al. An evaluation of risk factors for endometrial hyperplasia in premenopausal women with abnormal menstrual bleeding. Am J Obstet Gynecol 1999;181(3):525-9.

[13] Ballard-Barbash R, Swanson CA. Body weight: estimation of risk for breast and endometrial cancers. Am J Clin Nutr 1996;63(3 Suppl):437S-41S.

[14] Gibson M. Reproductive health and polycystic ovary syndrome. Am J Med 1995;98(1A):67S-75S.

[15] Morgan RW. Risk of endometrial cancer after tamoxifen treatment. Oncology 1997;11(2 Suppl 1):25-33.

[16] Barakat RR. Benign and hyperplastic endometrial changes associated with tamoxifen use. Oncology 1997;11(2 Suppl 1):35-7.

[17] Brand A, Dubuc-Lissoir J, Ehlen TG, et al. Diagnosis of endometrial cancer in women with abnormal vaginal bleeding. J Soc Obstet Gynaecol Can 2000;22(1):102-4. 